\title{
O coração e seus cuidados: interações entre medicina da alma e medicina do corpo em sermões brasileiros do século XVII e XVIII
}

\author{
The heart and its care: interactions between soul \\ medicine and body medicine in Brazilian sermons \\ from the seventeenth and eighteenth centuries
}

\section{Marina Massimi}

Docente do Departamento de Psicologia e Educação da Faculdade de Filosofia, Ciências e Letras da Universidade de São Paulo em Ribeirão Preto, é especialista em história da psicologia e das ideias psicológicas, Ribeirão Preto, SP - Brasil, e-mail: mmassimi3@yahoo.com

\section{Resumo}

O presente artigo analisa o emprego da metáfora do coração em sermões pregados no Brasil no período colonial, buscando apreender seu significado e função no universo cultural da época e no âmbito da tradição ocidental. 0 coração adquire um papel especialmente relevante tendo em vista seu lugar central na vida espiritual, segundo a perspectiva bíblica, e tendo em vista sua dimensão de interface entre a dimensão somática e a dimensão psicológica, dimensão esta ressaltada pela ciência médica e pela antropologia filosófica. Em virtude do fato de expressar as três dimensões fundamentais da pessoa 
humana, o coração torna-se então o órgão mais representativo do ponto de vista antropológico e teológico. O pregador encarrega-se de transmitir esse conhecimento acerca do coração e também se coloca como médico de suas enfermidades.

Palavras-chave: Coração. Oratória sagrada. Medicina do ânimo.

\section{Abstract}

This article examines the use of the metaphor of the heart in sermons preached in Brazil in the colonial period, seeking to understand its meaning and function in the cultural universe of the period and within the Western tradition. The heart acquires a specially relevant role taking into account its central place in the spiritual life according to Biblical perspective and taking into account its interface dimension between the somatic dimension and the psychological dimension, a dimension which is highlighted by the medical science and the philosophical anthropology. Due to the fact of expressing the three basic dimensions of the human being, the heart becomes the most representative organ in the anthropological and theological point of view. The preacher is responsible for transmitting this knowledge about the heart and also stands as a doctor of its diseases.

Keywords: Heart. Sacred oratory. Soul medicine.

O emprego frequente da metáfora do coração em sermões pregados em diversas localidades do Brasil ao longo dos séculos XVII e XVIII conforma-se plenamente ao significado a ela atribuído pela teologia simbólica desde Dionísio Areopagita (450-535), que afirma, em De divinis nominibus (Dos nomes divinos), que o coração é "símbolo de uma vida conforme a Deus e que difunde com sua bondade sua própria potência vital sobre os seres submissos à sua Providência" (AREOPAGITA, 2004, p. 193).

As significações assumidas pela metáfora são múltiplas, mas um elemento comum a todas elas é que a tematização do órgão, suas funções e também suas patologias, constitui-se numa interface entre os conhecimentos médicos da época e o gênero da medicina da alma. Com efeito, o coração é tido como sede da alma sensitiva nas perspectivas aristotélica e 
aristotélico-tomista: sendo assim, representa o elo entre a corporeidade e a vida psíquica e espiritual e tem, portanto, uma função importante em todas as dimensões da vida humana.

\section{O coração e suas funções segundo Luís de Granada}

Fontes muito importantes que veicularam essa concepção na formação dos pregadores brasileiros foram as obras do pregador espanhol Luís de Granada (1504-1588), muito difundidas e lidas por serem a referência mais importante da oratória sagrada na época. Dentre outros, destaca-se o texto Memorial de la vida cristiana (1578/1945) - no capítulo VII, chamado "Del conoscimiento de si mesmo" (GRANADA, [1578] 1945, p. 371-376), Granada aborda o tema em profundidade.

No tratado, Luís de Granada considera o coração como um órgão sobremaneira quente e duro, e detalha sua função no âmbito do sistema circulatório. Mostra que os produtos da nutrição e da digestão, uma vez que forem processados pelo fígado, são transformados em sangue e purificados dos demais humores nocivos, alcançando o coração, onde são formados (no ventrículo esquerdo) os espíritos vitais:

Y purificada ya esta, y despedida la cólera y melancolia com la superfluidad de lo que bebemos, se dispone para ir al seno derecho del corazon. Y en este se refina y purifica mas para ir al seno é ventriculo izquierdo, donde se forman los espiritus vitales; y esos asi dispuestos vienen a ser materia de que se engendran los otros espíritus mas nobles, que son los que dejimos llamarse animales (GRANADA, [1578] 1945, p. 253).

Na capítulo vigésimo sétimo ("Introduccion para tratar del ánima sensitiva y de los espíritus animales"), Granada trata das potências da alma sensitiva. Fiel à tradição aristotélico-tomista, proclama que alma é "una, simples, y espiritual substancia", e que possui três potências (GRANADA, [1578] 1945, p. 253): vegetativa, sensitiva e racional. A faculdade sensitiva é comum a todos os animais e mais nobre do que a faculdade vegetativa. Granada afirma existir no corpo, além do fígado e do coração, um terceiro lugar, onde se forjam os espíritos animais, ou seja, 
os espíritos por meio dos quais vemos, ouvimos, gostamos, tocamos e nos movemos (e que por essa razão os latinos chamaram de "animais"): o siso, localizado na parte mais alta do corpo, junto aos olhos, que são as sentinelas da "fortaleza" de nosso corpo.

Por fim, Granada aborda a descrição dos espíritos vitais e animais, na perspectiva dos médicos e dos filósofos. Tratam-se de instrumentos delicados, aptos a manter o governo da alma sobre o corpo, por terem uma constituição mista:

el anima que tenemos en nuestros cuerpos, es primer principio y causa de la vida que vivimos, y de los sentidos y movimiento que tenemos. Lo cual se ve claro, pues faltando el ánima, todos estos oficios y movimientos faltan, no faltando los miembros y sentidos de que ella se servia; pues al parecer se queda la misma figura y materia de los ojos, de los oídos, y de todos los otros órganos y sentidos sin hacer sus oficios. Pues como nuestra ánima sea espíritu (como son los ángeles) era necesario que los instrumentos próximos y inmediatos della se pareciesen y proporcionasen com ella; y, ó fuesen puramente espirituales, ó lá lo ménos se llegasen mucho á la condicion y nobleza dellos, cuales son los espiritus de que el ánima se sirve para darnos vida, y mucho mas los animales, que son como unos rayos de luz, mediante los cuales nos da sentido y movimiento. Porque de otra manera desproporcion grande fuera que una substancia puramente espiritual (cual es una ánima) tuviese por instrumento próximo y imediato un pedazo de nuestra carne, ó algun hueso grande. Esta es pues la causa por que ponemos este linaje de espiritus que son mas vecinos y proporcionados á la dignidad y naturaleza de nuestra ánima, que (como dijimos) es substancia espiritual (GRANADA, [1578] 1945, p. 254).

No capítulo trigésimo terceiro, "De la parte afectiva de la alma sensitiva; que es de las pasiones y afectos que están en nuestro corazon", Granada aborda o estudo da dimensão afetiva do psiquismo humano que pertence à alma sensitiva. Nela estão os afetos e as paixões naturais, "los cuales sirven para apetecer y procurar las cosas provechosas, y huir las dañosas, que no ménos son necesarias para la conservacion de nuestra vida y de cualquier animal" (GRANADA, [1578] 1945, p. 261). Dentre eles, há dois principais afetos, que são raízes e fundamentos dos demais: amor e ódio, também finalizados à conservação do indivíduo. 
Porque faltando estes dos afectos, quedaria el animal, ó como ave sin alas, ó galera sin remos, para no poder buscaro lo que o era provechoso, y huir lo contrario. Por lo cual dijeron muy bien los filósofos estoicos (como refire Séneca) que estos dos afectos eran como un anyo que la divina Providencia habia dado al hombre. Porque así como el ayo que tiene á cargo un niño, le procura todo bien, y le desvia de todo mal, así lo hacen estos dos afectos cuando son bien regidos (GRANADA, [1578] 1945, p. 261).

Tais afetos são as raízes principais das quais nascem os outros.

Porque del bien que amamos, cuando está ausente nace deseo, y cuando está presente tristeza. Y estas seis pasiones que son amor y odio, deseo y huida, alegría y tristeza, llaman los filósofos la parte concupiscible de nuestra ánima; porque tiene por oficio cobiciar estos bienes sensibles. Mas si este bien á que estamos aficionados es dificultoso de alcanzar, el deseo délo nos hace tener esperanza que lo alcanzarémos; porque facilmente esperan los hombres lo que desean. Mas si son tales las dificuldades, que vencen nuestra esperanza, luego nace de aqui outro afecto contrario, que es desconfianza. Otras veces si el deseo es muy grande, causa en nuestros corazones outra pasion, que es animosidad y osadia para omper por cualesquier dificultades que nos impidam este bien que deseamos [...] Mas si son tantas las dificuldades que no se atrevan á ellas, de aqui nace outra pasion contraria á la pasada, que es temor. El cual tambien sirve á la guarda del animal, para que no se atreva á lo que no puede, y para que busque su remedio ó escondiendose, o huyendo. Pero si demas desto se atreviesa alguno que totalmente nos impide lo que mucho deseamos, ó nos quita de las manos lo que ya poseemos, aquí se encrespa y embravece la ira: la cual se dice que es vengadora de los agravios y estorbos que recibe nuestra concupiscencia. De suerte que ella es como espada que se pone á defender esta pasion que tiene por hermana. Estos cinco afectos y pasiones naturales son tambien necesarios para la conservacion de nuestra vida (GRANADA, [1578] 1945, p. 261).

Os onze afetos são localizados no coração, pois, como já vimos, os dois ofícios da alma sensitiva - conhecimento sensorial e apetite - estão localizados nos membros principais do corpo humano, que são a cabeça e o coração,

lo cual experimentamos cada dia; porque manifiestamente sentimos encenderse la sangre del corazon com la ira; y apretarse com la tristeza, y dilatarse com el alegria; los cuales dos afetos pueden crecer tanto, que 
destemplen de tal manera el corazon, que nos quiten la vida, como muchas veces acaesce (GRANADA, [1578] 1945, p. 263).

Nessa concepção, não há, portanto, uma submissão necessária do corpóreo ao espiritual; pelo contrário, a localização fisiológica dos apetites no coração - o nó inquebrantável entre a compleição física e a alma - aponta também para a possibilidade do processo inverso (ZANLONGHI, 2002, p. 222). Os afetos são tidos como "fontes de vitalidade e de energia psíquica".

A importância dos afetos e suas influências (às vezes nefastas) no plano orgânico é enfatizada também na literatura jesuítica, bem como na cultura da época em geral. Os tratados Conimbricences, por exemplo, que como sabemos foram a matriz da formação dos jesuítas luso-brasileiros no período colonial (MASSIMI, 2002), atribuem grande importância a estes estados da alma definidos como paixões, e que na linguagem da psicologia moderna correspondem às emoções ou sentimentos. As paixões são entendidas como movimentos do apetite sensitivo, provenientes da apreensão do bem ou do mal, acarretando algum tipo de mutação não natural do corpo. Nesse sentido, elas dependeriam sempre de uma representação que o intelecto faz de algum objeto julgado como bom ou mau. Como o apetite sensitivo tem sua localização orgânica no coração, é possível que um movimento muito brusco chegue a causar o óbito.

Uma vez que evidenciamos a significação do coração na literatura formadora dos pregadores brasileiros, abordaremos agora a tematização do mesmo nas fontes objeto do nosso estudo, a saber, sermões pregados por oradores brasileiros, da Companhia de Jesus como das demais ordens religiosas e dos clérigos atuantes no Brasil da época. Podemos verificar assim que nesses documentos evidenciam-se diversas funções do coração humano. Em primeiro lugar, sua importante função fisiológica.

\section{0 coração como o centro vital do corpo}

O pregador beneditino Mateus da Encarnação Pinna (1687-1724), no sermão proferido na ocasião de Primeiro Domingo de Quaresma, em 1738, no Rio de Janeiro (MASSIMI, 2005), afirmava que no seio de "tão 
maravilhosa fábrica do composto humano, que com ela se acredita de admirável a sabedoria de seu Autor", a saber o corpo, "é o coração a parte mais nobre". Com efeito, o coração "á a fonte de que emanam os alentos vitais para todo o corpo: é tão puro, que não admite em si a mínima corrupção: é o primeiro móvel do nosso abreviado mundo, porque do seu movimento pende o das demais partes orgânicas [...] as operações do corpo lhe são todas subordinadas" (PINNA, 1752, p. 311-312).

\section{O coração como sede dos afetos}

Noutro sermão pregado pelo mesmo monge, na ocasião da celebração da "Soledade" de Nossa Senhora, junto ao Hospital da Santa Casa da Misericórdia no Rio de Janeiro, em 1739, o coração é abordado como sede dos afetos, e são descritos especificamente os efeitos da presença nele de emoções entre si contrastantes:

em um mesmo coração dois afetos contrários ou duas paixões opostas, e repugnantes, naturalmente não podem ser mui intensas; precisamente hão de pugnar entre si, como contrarias, e rebatendo-se de parte a parte, hão de perder a atividade própria; porque neste combate cada uma diminui a sua intenção. Isto experimentamos, quando no maior prazer da vida nos sobrevêm uma pena grande; porque logo se diminui o gosto, com que estávamos tão alegres: e ordinariamente o sobressalto, com que receamos qualquer desgraça, é bastante para rebater em nós qualquer alegria na ocasião dela. Logo também a certeza, com que esperamos um prazer grande, bastará para nos aliviar de uma grande pena (PINNA, 1752, p. 179-180).

O carmelita Eusébio de Mattos, ao retratar a intensidade das dores de Nossa Senhora aos pés da cruz, num sermão pregado em Salvador da Bahia, compara o movimento do coração, causado pela presença de afetos intensos, a um "mar de lágrimas": "o coração estava feito um mar de lagrimas; e [...] como o vento dos suspiros se representava todo sobre o coração, estava mui tempestuoso o mar". E continua: "estando assim o coração da Senhora em uma tormenta desfeita, nublou-se o entendimento" 
dela e por fim "se lhe escureceu o dia: as nuvens eram de tristeza, e estava todo aquele Céu coberto de nuvens; estas, pois embebendo em si todos os tormentos da Alma, e todas as amarguras do coração cheias de dor, e prenhes de sentimento, começarão a desatar-se pelos olhos, ou em lagrimas a dilúvios". Esse choro, segundo Mattos, originava-se no coração e no entendimento (MATTOS, 1694, p. 216).

Referindo-se às inquietações dos afetos humanos no coração, Vieira recorre às imagens de um vaso de barro cheio de vapores semelhantes a ventos impetuosos e entre si contrários:

E que tudo isto há-de caber em um coração de barro? Abalam-se e rebentam os montes; sai de si o mar; enfurecem-se os ventos; fulminam as nuvens; escurece-se e descompõe-se o céu; nem cabe em si mesmo o mundo com quatro vapores insensíveis que se levantam da terra: e que em um vaso tão estreito e tão sensitivo como o coração humano, hajam de caber juntas, e estar em paz todas estas contrariedades? (VIEIRA, 1993, v. 1, p. 720).

No século XVIII, o jesuíta Antônio Aleixo, em sermão pregado em Belém do Pará na ocasião das exéquias do Rei Dom João V, refere-se ao coração como fonte e sede de afetos dolorosos que saem dele semelhantes a rios: "nascem elas no fundo do coração, como em sua fonte; e se como rios nascem, também como rios correm" (ALEIXO, 1744, p. 4).

\section{O coração como centro da pólis}

O uso da metáfora do coração é muito frequente nos sermões também para indicar o papel do príncipe na monarquia. ${ }^{1}$ Esta é concebida como um corpo organizado por volta de um princípio único, o coração, conforme o modelo aristotélico prega. De modo similar, Aegidius de Viterbo (14691532) definira o príncipe como coração, mas também como alma do corpo. Essas metáforas pertencem a uma clara linha de argumentações a favor da

10 paralelismo entre príncipe e coração encontra-se em diversos textos: De Regno ad Regem Cypri I, 2, de Tomás de Aquino; De regimine principum libri III, de Aegidius Romanus (III, II, 3); os comentários à política aristotélica de Petrus de Alvernia (Scriptum super librum Politicorum, III, 12); De potestate regia et papali II, 5, de Johannes Parisiensis; De regimine Christiano de Jacobus de Viterbo; Monarchia de Dante Alighieri $(I, 3)$.

Rev. Pistis Prax., Teol. Pastor., Curitiba, v. 3, n. 2, p. 521-539, jul./dez. 2011 
monarquia, que por meio do paradigma fisiológico aristotélico, afirma o naturalismo político, passando-se de uma visão originária que estabelece um paralelismo acerca do corpo e sociedade para uma concepção da sociedade como organismo. Com efeito, o uso dessa metáfora polivalente parece garantir o princípio de que a organização social e política realizada pelos homens deve imitar a natureza. A escolha de uma ou de outra interpretação da metáfora depende das finalidades da argumentação de cada autor. Dentre as outras, a analogia entre o príncipe e o coração visa a enfatizar a superioridade do regime monárquico (SKINNER, 1996).

\section{O coração como centro do eu, da pessoa}

Referências ao coração como sendo o centro da pessoa humana são frequentes em muitos sermões, dentre os quais destacamos alguns. Antônio Vieira, na quinta quarta-feira de 1669, prega em Lisboa um sermão dedicado à cegueira tomada em suas diversas dimensões, e sintetiza na frase "os olhos veem pelo coração" (VIEIRA, 1993, v. 2, p. 111) a doutrina pela qual os afetos (que têm sede no coração) determinam nos homens a visão e a concepção da realidade, quando não colocados de modo ordenado ao domínio da racionalidade. Desse modo, os afetos desordenados, e não a ignorância, seriam a causa dos erros humanos. Nesse sentido, afetos e coração ocupam um lugar central na estrutura da pessoa.

No sermão pregado na quinta dominga de Quaresma de 1654 em São Luís do Maranhão, Vieira aproxima o dinamismo dos afetos desta vez não mais ao sentido da vista, e sim do ouvido: afirma que o coração também ouve e que cada um ouve conforme o coração: "Os corações também têm orelhas: e estais certos que cada um ouve, não conforme tem os ouvidos, senão conforme tem o coração e a inclinação" (VIEIRA, 1993, v. 2, p. 169).

No sermão do Mandato pregado em 1655 na Misericórdia de Lisboa, Vieira afirma que o coração é o primeiro móvel do mundo pequeno que é o homem e, no Sermão de São Bartolomeu, afirma que os homens devem ser julgados pelo coração, sinônimo do centro da vida anímica interior e invisível: "o coração, em que consiste o ser, o valor, e a diferença de homem a homem" (VIEIRA, 1993, v. 3, p. 625). Normalmente os homens 
não podem ver o coração dos seus semelhantes, mas Deus os vê. Por isso, o juízo humano sempre é limitado.

Por que o coração assume tanta importância do ponto de vista teológico? Por ser o lugar do amor esponsal, onde acontece a aliança do divino com o humano e a identificação de um com o outro. É justamente no nível do coração que ocorre o primeiro reconhecimento do mistério pelo homem: assim, é recorrente a metáfora da imagem do Amado esculpida no coração.

No século XVIII, a valorização do coração como sendo o núcleo central do humano e o ponto de contato com o transcendente é presente inclusive nos textos dos cientistas: um exemplo é o cientista italiano Eugenio Magalotti, que, nas suas Lettere Familiari (1741), supõe a existência de uma sorte de instinto natural para o reconhecimento da divindade, que seria próprio de todos os povos da terra, pelo qual o homem teria o sobrenatural como que esculpido no coração. Tal inclinação, a qual pode assumir as múltiplas formas do desejo humano, é descrita utilizando uma analogia derivada do mundo dos sentidos: assim como, do ponto de vista do gosto, variam os objetos, mas não o desejo, da mesma forma, "a sede de cada um é, de formas diferentes, um anseio perene pelo sentido espiritual" (MAGALOTTI, 1741 apud JORI, 1998, p. 246). ${ }^{2}$

Outro pregador jesuíta, Ângelo Reis, num sermão dedicado ao grande santo missionário jesuíta Francisco Xavier e pregado no Colégio da Companhia no Rio de Janeiro em 1703, ao dissertar acerca do amor, descreve o amor como uma ligação:

Amar eu por escolha, supõe da parte do objeto amado uma tal, e tão singular prerrogativa, que por ela me move, e excita a que escolhidamente ame; e porque esta prerrogativa, ou atributo singular, só se acha naquele

2 Magalotti retoma um trecho de Juan de la Cruz (Llama de amor viva): "Estas cavernas são as potências da alma, memória, entendimento e vontade; as quais são tão profundas, quanto de grandes bens são capazes, pois não se ligam com menos, que com o infinito [...]. Quando estão vazias e limpas, é intolerável a sede, e a fome, e ânsia de sentido espiritual. Como Deus pode dar ao infinito, assim pode a alma receber ao infinito, e como Deus é onipotente no agir, assim também a alma é, para assim dizer, onipotente no padecer" (MAGALOTTI, 1741 apud JORI, 1998, p. 247). Esse vazio inesgotável da alma é o negativo, a forma humana de Deus: "Sendo que neste vazio há um infinito espaço côncavo, se é verdade que o axioma que Deus e a natureza nada fazem em vão, precisará também acreditar que seja um espaço convexo também infinito, suficiente para preencher este espaço côncavo" (MAGALOTII, 1741 apud JORI, 1998, p. 246).

Rev. Pistis Prax., Teol. Pastor., Curitiba, v. 3, n. 2, p. 521-539, jul./dez. 2011 
Amante que se aperta e ata pelo amado; por isso só aquele amante que assim se ata e se aperta pelo amado, só esse deve ser amado escolhidamente (REIS, 1709, p. 11).

Mas é o sermão do beneditino frei Ruperto de Jesus, o documento que mais claramente descreve o coração como sendo o lugar dessa aliança entre ser humano e ser divino: o coração é, em suas palavras, o lugar do estampar-se do amado de modo a acontecer uma identificação do amante com o amado. O sermão pregado em 1697, na Bahia, na ocasião da inauguração da nova igreja dos Carmelitas Descalços, é dedicado à vida de Santa Teresa, a partir de dois versículos, um do Evangelho escrito por Mateus, (cap. 25): "Clausa est janua", e outro do livro da Apocalipse (cap. 11, v. 12): "Apertum est templum: visa est arca Testamenti, signum magnum apparuit, Mulier". Ruperto afirma que Cristo realizou em Teresa uma nova encarnação, e compara a encarnação na vivência de Teresa à estampa e impressão do Amado no corpo e na alma da Amante:

A traça foi imprimir-se e estampar-se na carne do coração de Teresa. Esta casta Encarnação [...] não veio a ter efeito, senão no coração de Teresa. De tal sorte imprimiu Cristo a sua estampa no coração de Teresa, que Cristo e Teresa pareciam a mesma cousa (JESUS, 1699, p. 12).

Esse tipo de relação é muito semelhante à que intercorre no seio da Trindade entre as três Pessoas Divinas:

In Divinis o Pai e o Filho ambos são a mesma cousa na essência: Ego et Pater unum sumus. Porque o Filho está estampado no coração do Pai, como seu Verbo, e o coração do Pai é que contem em si a estampa do Verbo seu Filho: Eructavit cor meum verbum bonum. Eis ai o Verbo estampado no coração do Pai: Hunc Pater signavit Deus. Eis ai o Pai estampando em si ao Verbo divino seu Filho; e isto que tem o Filho enquanto verbo no coração do Pai teve também o Filho de alguma sorte, enquanto Cristo no coração de Teresa: ut signaculum super cor. Encarnou imprimindo-se no coração de Teresa, para não haver entre ele e Teresa distinção alguma, assim como a não ha entre a obra e o que nela se imprime. O coração de Teresa foi a obra, e imprimindo-se Cristo nesta obra, Cristo ficou sendo o signaculum, 
o coração ficou sendo o assinalado: Pone me ut signaculum super cor tuum.

E ambos ficarão sendo a mesma cousa (JESUS, 1699, p. 12-13).

Ruperto diferencia a encarnação de Cristo do modo como ocorreu no seio de Nossa Senhora, da encarnação de Jesus no coração de Teresa: "a Encarnação feita na Senhora foi Encarnação feita por união, e a encarnação feita em Teresa foi encarnação feita por impressão" (JESUS, 1699, p. 12-13). E nesse sentido interessa especialmente o coração, sendo este o lugar do acontecer dessa união: "mediante a impressão é que Cristo se ajuntou no coração de Teresa: "ut signaculum super cor". Assim, a própria carne do coração de Teresa constituiu-se no substrato da encarnação de Cristo: "parece foi necessário viesse Teresa, para com a carne de seu coração suprir de alguma sorte esta falta". Desse modo, "assim como para encher as faltas da tua Paixão escolheu Cristo a carne do corpo de São Paulo, assim também podemos dizer que para encher alguma falta, que houve na sua primeira Encarnação, escolheu Cristo a carne do coração de Teresa" (JESUS, 1699, p. 12-13). Essa encarnação por impressão do divino na carne do coração humano, que ocorreu em Teresa, foi absoluta novidade:

uma cousa nunca vista, que é o encarnar por impressão; qual é imprimir a sua estampa na carne do coração de Teresa, e identificar-se com a carne daquele coração: Pone me ut signaculum super cor tuum (JESUS, 1699, p. 12-13).

Tema análogo recorre no sermão sobre o Evangelho de Mateus (cap. 16) do franciscano frei Agostinho da Conceição, pregado no Convento de Santo Antônio de Rio de Janeiro em 1681. Este define as chagas de Francisco como sinais da relação de amor entre o Divino Esposo e a Alma:

"Dizia o Esposo Divino àquela Alma santa, com quem se desposava: Esposa das minhas finezas, o que convosco quero obrar em desempenho do meu amor, é retratar-me em vós; e para o fazer, como desejo, quero que estampeis deste meu corpo no vosso, aquilo que pertence aos braços, e coração. Abraçai-vos comigo para este efeito, que o filete não imprime na cera mais que aquilo que em si tem aberto, e como o que neste meu corpo está aberto são os braços e coração, estampado no vosso, ficareis também como eu, nos braços e coração assinalada (CONCEIÇÃO, 1690, p. 17). 
Essa estampa tem caráter permanente, além da morte:

A motivo e desempenho do amor, ficavam tão identificados aqueles mesmos sinais e caracteres no corpo do Esposo e no da Esposa, que ainda que o Esposo se fosse para o Céu e a Esposa se ficasse na terra, em um e outro corpo se achariam, sempre indivisivelmente aqueles mesmos sinais, poderes e fortaleza do amor identificados (CONCEIÇÃO, 1690, p. 18).

O topos da impressão, da estampa no coração, liga-se a outro mais antigo da escritura no coração (BOLZONI, 2010). O topos do retrato da pessoa amada pintado ou esculpido no coração é muito antigo, sendo presente na tradição lírica ocidental desde a Idade Média. Segundo Bolzoni, não se constitui apenas numa metáfora linguística, mas adquire também consistência material; não se trata de simples analogias e sim de um trânsito entre o espírito e a carne, entre a palavra e o corpo. Estabelece-se uma relação entre a imagem física exterior e a imagem interior e espiritual.

O coração, lugar da interioridade, possui também evidência exterior pode-se dizer que seja o lugar de trânsito entre interioridade e exterioridade (BOLZONI, 2010). Possivelmente, esse fato deve ser interpretado a partir de uma tradição muito antiga que atribui dimensão espacial às potências anímicas, por exemplo, à memória (BOLZONI, 2010). As imagens interiores, chamadas também de "fantasmas" por essa tradição, referem-se também aos dinamismos afetivos. Quando alguém se apaixona pela vista de dado objeto, a imagem deste (fantasma) polariza o dinamismo dos espíritos vitais, ativando o movimento das potências apetitivas e intelectivas. O coração torna-se o repositório dessas imagens, de modo que se diz que a imagem do objeto amado se imprime no coração (BOLZONI, 2010).

\section{Os remédios das doenças do coração}

O coração pode ser o lugar da elevação do homem para além de si mesmo, mas pode ser também lugar de adoecimento. Nesse caso, o pregador se coloca como médico da alma eficiente em proporcionar-lhe os remédios adequados (MASSIMI, 2005). 
Como médico experiente, o já citado beneditino frei Pinna, no sermão já citado pregado no Rio de Janeiro em 1739, dedicado às dores de Nossa Senhora, coloca que "a eficácia de qualquer remédio (para a aflição) depende precisamente de ser aplicado onde a queixa tem a sua origem". E, ainda, que "será conveniente examinar os princípios dela, para que não erramos na aplicação dos remédios" (PINNA, 1752, p. 160).

O coração padece por ser o local dos afetos e da vontade: "Na alma, obra a memória, o entendimento, e a vontade, que são as potências receptivas e operativas dela; mas só a vontade se aflige, porque só a vontade padece". Com efeito, "a memória representa o passado; o entendimento até pelo futuro discorre; e com tudo nem no entendimento há aflição, pelo que alcança com o seu discurso; nem a memória recebe angustia"; mas é a vontade e os afetos que, associados aos discursos do entendimento e às lembranças da memória, causam o padecimento, de modo que "a pena, e o sentimento são atos só da vontade”. Porém, se faltarem as operações do entendimento e da memória que representam o objeto do sofrimento, a vontade e os afetos não padecerão: "não haverá aflição, ou pena para a vontade, se a memória e o entendimento cessarem de lhe propor motivos de se angustiar, e afligir" (PINNA, 1752, p. 160-161). Portanto, a diversão da memória e do entendimento é um recurso eficiente a ser usado nos padecimentos que afligem o coração: "esta é a razão, porque nas angustias e aflições do animo, o lenitivo mais aprovado é divertir da memória e do entendimento o que pode afligir, e angustiar a vontade" (PINNA, 1752, p. 160-161). Todavia, quando esses padecimentos são muito intensos, esse remédio é insuficiente, porque os excessos nos afetos impedem as operações do entendimento e da memória: "Porém, se a apreensão é tão viva, que nem o entendimento cessa de ponderar, nem a memória de se lembrar, próvida a natureza instituiu as lagrimas para desafogo da pena". O pranto constitui-se assim numa catarse do afeto, por proporcionar alívio imediato ao coração: de fato, os espíritos animais dos afetos penosos que o invadem podem dissolver-se e vazar do coração por meio das lágrimas: "pelos olhos parece que se destila em lagrimas um coração aflito; mas nessas lagrimas sai pelos olhos o mais destilado da pena, e o mais apurado do sentimento. Esta é a razão, porque depois das lagrimas o coração fica aliviado e diminuída a aflição" (PINNA, 1752, p. 161). 


\section{Desse modo, Pinna conclui seu argumento afirmando que}

divertir pois as representações da memória, suspender os discursos do entendimento, e desatar do coração as lagrimas; são os três remédios mais aprovados, que para alivio das penas inventou compassiva a natureza, e descobriu a industria: se o permitira o assumpto, recorrêramos aos Aforismos, que deram os Hipocrates de aflições profanas, e neles viramos aprovados os remédios, que apontamos (PINNA, 1752, p. 161-162).

Analisando os efeitos de cada um dos remédios, Pinna trata do "primeiro remédio para uma alma aflita na soledade", que consiste em "perder a memória do que perdeu". E afirma que

se a memória não repete lembranças, não pode atormentar a ausência. Vulgarmente dizemos, e é provérbio da experiência, que quando os olhos não veem, o coração não sente. Também se a memória se esquece, já a vontade se não aflige; porque neste ponto é a memória para a vontade, o mesmo que os olhos para o coração (PINNA, 1752, p. 165-166).

O segundo remédio, que consiste em "suspender os discursos do entendimento", se faz necessário pelo fato de que

não há maior tirano para uma alma, que está aflita, do que é o entendimento próprio. Quanto mais agudo para discorrer; tanto mais aguda se faz a pena para penetrar. Quanto mais apurado para ponderar; tanto mais apurado está o sentimento para afligir (PINNA, 1752, p. 175).

A imaginação de algo que remeta à positividade e dê esperança pode ser de grande ajuda também - a eficácia desse remédio se dá em virtude do fato de que "em um mesmo coração dois afetos contrários ou duas paixões opostas, e repugnantes, naturalmente não podem ser mui intensas". Com efeito, pelo fato de elas se oporem entre si, como contrárias, "rebatendo-se de parte a parte, hão de perder a atividade própria; porque neste combate cada uma diminui a sua intenção". Pinna comprova esse fato pela experiência:

Isto experimentamos, quando no maior prazer da vida nos sobrevêm uma pena grande; porque logo se diminui o gosto, com que estávamos 
tão alegres: e ordinariamente o sobressalto, com que receamos qualquer desgraça, é bastante para rebater em nós qualquer alegria na ocasião dela. Logo também a certeza, com que esperamos um prazer grande, bastará para nos aliviar de uma grande pena (PINNA, 1752, p. 179-80).

Por fim, o terceiro remédio, que é o pranto, tem o efeito de "desafogar o coração angustiado; por que oprimido não chegue a submergir-se na pena”. Pelas lágrimas, o afeto penoso se materializa e sai do coração, de modo a aliviá-lo do peso da pena:

Vistes sangrar-se um rio, para que a sua enchente não inunde os campos, e afogue as plantas? Pois nas aflições do animo isso mesmo intenta a providencia da natureza com as suas lagrimas. Como se dera uma sangria no coração faz que rompam as lagrimas, e saia nestas a amargura, em que o coração se oprime. Diz o sagrado texto que S. Pedro na precedente noite chorara com amargura: "Flevit amare". E como pode haver lagrimas com amargura? De que fonte nascem elas, para que possam trazer consigo amargura? Direi. As lagrimas tem virtude de extrair e trazer em si a qualidade, que acham no coração; e como o coração de S. Pedro estava cheio de amarguras pela contrição de sua culpa, saião dele as lagrimas trazendo em si a amargura do coração. Flevit amare. As águas que á imitação das lagrimas, artificialmente se destilam das flores, extraem delas as qualidades, que consigo trazem. Também as lagrimas trazem em si as qualidades que extraíram do coração, de que foram destiladas. Se o coração está aflito, saem as lagrimas com amargura [...] porque trazem em si a amargura, que havia no coração; mas por isto mesmo fica o coração aliviado; porque se lhe extraiu a amargura, que o afligia (PINNA, 1752, p. 188-189).

São imagens verbais que parecem não ter apenas valor de metáforas, mas sim sentido literal: desse modo, ao abordar a questão dos remédios das patologias do coração causadas pelo excesso dos afetos, reaparece novamente a natureza mista do mesmo: lugar de vivências psíquicas tais como os afetos, que também se materializam, adquirem peso e possuem qualidade materiais. 


\section{Conclusão}

Gallian (2010) aponta que "a tendência de concentrar todo o conteúdo essencial da vida psicológica e espiritual do homem no seu coração" caracterizou, na Antiguidade, a cultura dos povos semíticos (conforme atesta a Bíblia Sagrada, em que o coração é tido como centro e sede de todas as atividades anímicas e espirituais), bem como os gregos antigos: "através de textos fundamentais como os de Homero, Hesíodo e Ésquilo, em que o termo kardia remete a todo um universo de significados e ações que identificam a pessoa na sua integralidade" (GALLIAN, 2010, p. 29). Ele é tido "não apenas como sede dos sentimentos e das paixões, mas também da inteligência, dos pensamentos, e ainda como lugar de encontro com os deuses; lugar da inspiração divina" (GALLIAN, 2010, p. 29). Gallian aponta para a longa duração dessa tradição "cardiocêntrica" ainda na Idade Moderna, e afirma que, "ainda no século XVI europeu, é o coração e não o cérebro que, nas imagens dos filósofos e médicos, aparece caracterizado como o centro não apenas da vida física e emocional, mas também intelectual e moral" (GALLIAN, 2010, p. 31). Todavia, o advento na Idade Moderna da visão mecanicista do corpo humano, que se introduz com o advento da ciência experimental, infligirá um duro golpe a essa tradição.

Em plenos séculos XVII e XVIII, as fontes que aqui apresentamos apontam para o perdurar dessa concepção na cultura brasileira. Com efeito, os sermões trazem concepções antropológicas e cosmológicas advindas da tradição teológica e filosófica do Ocidente, encarregando-se de transmiti-las no contexto cultural brasileiro. A eficácia dessa transmissão é documentada pelo fato de que a importância do coração permanece viva na cultura brasileira até os nossos tempos. Noel Rosa, um dos grandes compositores e criadores do samba brasileiro, talvez pela influência devida ao fato de ter cursado, em 1931, um ano da faculdade de medicina, compôs a música "Coração", cujos versos dizem: "Coração, grande órgão propulsor/transformador do sangue venoso em arterial/coração, não és sentimental/mas entretanto dizem que és o cofre da paixão". 


\section{Referências}

ALEIXO, A. SI. Oração Fúnebre das Exéquias de Dom João V. In: MACHADO, D. B. Sermões de exéquias de reis de Portugal. Lisboa: Academia Real, 1744.

BOLZONI, L. Il cuore di cristallo. Torino: Einaudi, 2010.

CONCEIÇÃO, F. A. Sermão do Serafim Chagado Príncipe dos Pobres Evangélicos na Festividade que a Igreja Católica celebra em 17 de Setembro e a Venerável Ordem Terceira da Penitencia do Rio de Janeiro, como a orago soleniza na prodigiosa impressão das Chagas Santíssimas em o Seu Seráfico Corpo pelo mesmo Redentor que na Cruz para nosso remédio as recebeu. Pregado pelo mais indigno filho seu Frei Agostinho da Conceição, Lente de Teologia, ex-ministro Provincial da Santa Província Recoleta da Conceição do Rio de Janeiro, Estado do Brasil, em o Convento do Santo Antônio Ano de 1681. Dedicado à Mesma Venerável Ordem Terceira da Penitencia, em Cuja Solenidade se Pregou. Lisboa: Ferreira, 1690.

GALIAN, D. M. C. O destronamento do coração: breve história do coração humano até o advento da modernidade. Memorandum, n. 18, p. 27-36, 2010. Disponível em: <http://www.fafich.ufmg.br/ memorandum/a18/gallian01.pdf〉. Acesso em: 10 jan. 2010.

GRANADA, F. L. Memorial de la vida cristiana. In: GRANADA, L. Obras completas. Madrid: Biblioteca Autores Espanõles, 1945. Tomos II (organizada por D.B.C. Aribau).

JESUS, F. R. Sermão da Gloriosa Madre Santa Teresa na ocasião, em que os Religiosos Carmelitas Descalços abrirão a sua Igreja nova na Bahia, pregado pelo Muito Reverendo Padre Mestre Dr. Frei Ruperto de Jesus, Lente Jubilado em Teologia, Qualificador e Regedor do Santo Oficio, Monge do Patriarca S. Bento da Província do Brasil, no ano de 1697. Lisboa: Oficina De Manoel Lopes Ferreira, 1699.

JORI, G. Per evidenza: conoscenza e segni dell'età barocca. Torino: Marsilio, 1998. 
MATTOS, F. E. Sermões do Padre Mestre Frei Eusebio de Mattos, Religioso de Nossa Senhora do Carmo da Província do Brasil. Primeira Parte, Lisboa: Oficina de Miguel Deslandes, 1694.

MASSIMI, M. A psicologia dos jesuítas: uma contribuição à história das idéias psicológicas. Psicologia, Reflexão e Crítica, v.14, n. 3, p. 625-633, 2002.

MASSIMI, M. Palavras, almas e corpos no Brasil colonial. São Paulo: Loyola, 2005. PINNA, M. E. OSB. Viridiario Evangelico em que as Flores da Virtude illustrão com Discursos Moraes e os Frutos da Santidade se exornão com Panegyricos em Varios Sermões Parte I, II, III E IV dedicada e offerecida ao Reverendissimo Padre Fr. Joseph de S. Maria, Doutor Jubilado de Sagrada Theologia e Dignissimo Geral que foy da Religião de São Bento de Portugal e Brasil. Lisboa: Ocidental. Officina da Música. 1752.

VIEIRA, A. Sermões. Porto: Lello e Irmão, 1993. v. 5.

RAIMONDI, E. Trattatisti e narratori del seicento. Milano-Napoli: Ricciardi, 1965. v. 36.

REIS, A. SI. Sermão da Canonização do Grande Apostolo do Oriente S, Francisco Xavier Pregado no dia da Mesma Sesta, no Colégio de Rio de Janeiro Pelo P. Ângelo dos Reis da Companhia de Jesus, da província do Brasil Ano de 1703 Esteve Exposto O Santíssimo Sacramento. Lisboa: Costa Deslandes, 1709.

SKINNER, Q. The foundations of modern political thought. Cambridge: Cambridge University Press, 1978.

ZANLONGHI, G. Teatri di formazione: actio, parola e immagine nella scena gesuitica del Sei/settecento a Milano. Milano: Vita e Pensiero, 2002.

Recebido: 30/01/2011

Received: 01/30/2011

Aprovado: 02/03/2011

Approved: 03/02/2011 